\title{
Effect of animated movie in combating child sleep health problems
}

\section{Citation}

Surani, Salim R, Saherish S Surani, Sreevidya Sadasiva, Zoya Surani, Amina Khimani, and Sara S Surani. 2015. "Effect of animated movie in combating child sleep health problems." SpringerPlus 4 (1): 343. doi:10.1186/s40064-015-1130-4. http://dx.doi.org/10.1186/s40064-015-1130-4.

\section{Published Version}

doi:10.1186/s40064-015-1130-4

\section{Permanent link}

http://nrs.harvard.edu/urn-3:HUL.InstRepos:17820761

\section{Terms of Use}

This article was downloaded from Harvard University's DASH repository, and is made available under the terms and conditions applicable to Other Posted Material, as set forth at http:// nrs.harvard.edu/urn-3:HUL.InstRepos:dash.current.terms-of-use\#LAA

\section{Share Your Story}

The Harvard community has made this article openly available.

Please share how this access benefits you. Submit a story.

Accessibility 


\title{
Effect of animated movie in combating child sleep health problems
}

\author{
Salim R Surani ${ }^{*}$, Saherish S Surani ${ }^{2}$, Sreevidya Sadasiva ${ }^{2}$, Zoya Surani ${ }^{2}$, Amina Khimani ${ }^{3}$ and Sara S Surani ${ }^{4}$
}

\begin{abstract}
Objective: Sleep deprivation among teens is a major health issue. Only $15 \%$ of teens get $8.5 \mathrm{~h}$ of sleep on school nights. Sleep deprivation can lead to poor grades, sleepiness and moodiness. We undertook a study to assess the prevalence of sleep habit disturbance among elementary school students in South Texas with Hispanic ethnicity predominance. We also found how much a video based on sleep education had an impact on these children.

Method: Once the Corpus Christi Independent School District (CCISD) approved the collection of baseline sleep data, questionnaires were administered using the Children's Sleep Habit Questionnaire (CSHQ.) These questionnaires were distributed prior to the viewing of the educational and animated movie KNIGHTS (Keep Nurturing and Inspiring Good Habits in Teen Sleep). Four months later, a random follow-up was performed and the children were requested to respond to the same CSHQ.
\end{abstract}

Results: 264 children from two elementary schools participated in this educational program. At baseline, 55.56\% of the children had trouble sleeping. When the questionnaire was administered four months later, only $23.26 \%(p<0.05)$ had trouble sleeping. Additionally, at baseline, approximately 60-70\% children had some baseline bedtime resistance, anxiety dealing with sleep, issues with sleep duration and/or awakenings in the middle of the night. In the follow up questionnaire, results showed significant improvements in overall sleep habits, bedtime resistance, sleep anxiety and night awakenings amongst students $(p<0.05)$. However, no significant differences were seen in sleep duration and daytime sleepiness.

Conclusion: Sleep deprivation and good sleep habits remain as a pervasive challenge among elementary school students. Administering an animated video about sleep education along with a provider-based education may be an effective tool for educating elementary school students and decreasing the prevalence of these sleep-related issues. Future prospective randomized studies are suggested.

Keywords: Sleep deprivation, Teen sleep, Video based learning, Sleep education

\section{Background}

Sleep deprivation and sleep problems are common among adolescents. Sleep deprivation occurs when one does not get enough sleep. It can also lead to impairment of the cognitive function (Nixon et al. 2008; $\mathrm{Ng}$ et al. 2009; Iwadare et al. 2013). The average adult needs about seven to $8 \mathrm{~h}$ of sleep per night, while adolescents need about $9 \mathrm{~h}$ of sleep in order to feel alert, well rested, and for optimal performance in the domain of cognitive

\footnotetext{
*Correspondence: srsurani@hotmail.com

${ }^{1}$ Texas A\&M University, 1177 West Wheeler Ave, Suite 1, Aransas Pass, TX 78336, USA

Full list of author information is available at the end of the article
}

process, school performance, mood regulation and health (Mercer et al. 1998; Anderson et al. 2009; Wolfson and Carskadon 1998).

Approximately 15 million American children are affected by inadequate sleep (Smaldone et al. 2007). Most teens do not get enough sleep as well, and only $15 \%$ of teens report sleeping at least $8.5 \mathrm{~h}$ on school nights (Carskadon et al. 1998). Studies have shown that teens are more inclined to have irregular sleep patterns across the week, and tend to stay up late and sleep in late on weekends. This is detrimental to their biological clock and affecting their quality of sleep. $70 \%$ of the teens have their bedtime at $10 \mathrm{pm}$ or later. The most common reason accounted for delayed sleep time is attributed to

\section{贷 Springer}


homework (46\%), hanging out with friends (30\%), television $(39 \%)$, stress $(42 \%)$, or part-time job $(21 \%)$, to name just a few (Noland et al. 2009).

Approximately $90 \%$ of parents feel that their children are getting adequate sleep. On the other hand $60 \%$ of adolescents reported difficulty in getting out of bed in the morning and the majority of them require their parents to wake them up for school (Carksadon et al. 2006; Wolfson et al. 2003; Crowley et al. 2006).

The study from Australian Centre for Education in Sleep (ACES) showed significant improvements of sleep knowledge were as the New Zealand trial showed significant improvements in both week and weekend sleep duration. Positive feedback regarding the program was received from both teachers and students involved in these trials. Overall, the ACES sleep education programs have proved that these programs are capable of improving sleep duration and knowledge amongst adolescents. The findings in this study show promising signs that interventions amongst adolescents can indeed improve sleep knowledge and overall sleep hygiene, thus improving sleep-related psychological, social, and health issues (Moseley and Gradisar 2009).

The ACES intervention involved implementation in a lecture-based style involving PowerPoint presentation. However, studies have shown that students prefer sleep education to be more interactive, and less monotonous. From the literature it was very clear that adolescents were encountering significant challenges due to sleep deprivation, delayed phase syndrome and challenges due to inadequate sleep. Thus, we undertook a study to assess the baseline sleep data and education of the elementary school students to help create healthy sleep habits. We designed and produced a 3D animated sleep education movie KNIGHTS (Keep Nurturing and Inspiring Good Habits in Teen Sleep) to help create healthy sleep habits.

\section{Objective}

To assess the baseline sleep habit among elementary school children and to assess the role of media based interventions, in result, having a positive effect.

\section{Methods}

For this study, permission was obtained from the CCISD (Corpus Christi Independent school District) as a part of broader sleep education program. The children underwent survey at baseline and after the intervention (animated movie). Parental consent was not required as the program was done as an educational activity, and pre and post intervention survey was conducted.

Baseline sleep data was collected from the 4th and 5th grade elementary school children by using Children Sleep Habit Questionnaire-Sleep Self Report Form
(CSHQ-SSRF). Both schools have the Hispanic ethnicity predominance with $52 \%$ of their children being of Hispanic ethnicity. CSHQ-SSRF form assessed the children sleep habits in the domain of bedtime resistance, sleep onset delay, sleep anxiety, and sleep duration, night awakening and daytime sleepiness. CSHQ is a validated tool showing good internal consistency for both the community and clinical sample (Owens et al. 2000). Sleep duration, bedtime resistance, daytime sleepiness, and sleep anxiety showed the highest internal consistencies. The Sleep Self Report Form is a 26-item survey, which is designed to assess sleep domains similar to the CSHQ. The items were rated based on a 3-point scale. This ranged from usually 5-7 times a week, sometimes 2-4 times a week, and rarely $0-1$ times a week. In this survey instrument, higher scores indicate more abnormal sleep (Owens et al. 2000).

Each session comprised of 45-50 min with an average of 30-40 children in each session. Trained middle school children who underwent a 2-h training session from a board certified sleep specialist and the Registered Respiratory therapist conducted the session. Training sessions included basic education about teen sleep, viewing of the movie KNIGHTS and a question and answer (Q\&A) session on any sleep questions they had and questions they could have encountered during the session.

The session started with the introduction of the teen moderators, and administration of the pre-questionnaire. This was followed with the viewing of the movie KNIGHTS (approximately $19 \mathrm{~min}$ ). This was the first 3D animated movie produced by It's Your Life Foundation (https://www.itsyourlifefoundation.org). This can be viewed from the foundation site or from https://www. youtube.com/watch?v=RwjrXJ4e-0Y. This was followed by a $\mathrm{Q} \& \mathrm{~A}$ session. The trained project coordinator were also available during the session to address any questions which the teen moderator may not have been able to answer.

Four months later, an unannounced random survey was carried out by the administration of the CSHQ-SSRF, again.

\section{Statistics}

Statistical analysis was performed using R Statistical Software (Foundation for Statistical Computing in Vienna, Austria). The proportion of responses to the pre-intervention questionnaire was calculated to determine baseline sleep habits and problems. The mean scores were calculated for each question and the overall questionnaire. $T$ test was performed on the mean scores $(\mathrm{p}<0.05)$ to detect the differences between the pre and post-intervention. The proportion of responses of each question was compared between the pre and post-intervention 
groups using contingency tables with a statistical significance of $(p<0.05)$ which was determined using the Pearson Chi square test statistic.

\section{Results}

The questionnaire was answered by 264 elementary school students, of which 166 were in 4th grade and 98 in 5 th grade respectively. The total sample size and missing data is detailed in Table 1.

The results are divided into 3 parts namely,

Elementary School Pre-Intervention Data Report.

Elementary School Post-Intervention Data Report.

Comparison between Pre and Post-Intervention Data.

\section{Pre-intervention results}

The Pre-intervention data is summarized in terms of mean questionnaire scores, response percentages to the questionnaire and comparison between grades 4 and 5 .

Questionnaire scores The sum of the scores for the whole questionnaire (questions 2 through 26) has a possible maximum score of 73 and a minimum score of 23 . In the pre intervention data, the questionnaire scores ranged from 29 to 57 with a mean and median of 45 , as can be seen in Figure 1.

Response percentages Of the 264 students, 56\% had trouble sleeping and $21 \%$ did not like to sleep. Among the different blocks (Table 2), 30-50\% of students had major sleep issues in block 1 of the questionnaire (bedtime resistance). In the block 2, 3, 4, 5 and 6, 10-30\% of students had problems. $50 \%$ of the students rarely slept in the same bed and were not ready to sleep at the usual bedtime. Only a third of the students fell asleep within $20 \mathrm{~min}$. 36\% rarely felt rested after a good nights sleep (Table 3).

Comparison between grades 4 and 5: We also did the comparison between the students between grade 4th and 5 th grade. There is a significant difference in the percent of students who had trouble sleeping, 63\% in grade 4 compared to $43 \%$ in grade 5 . (Chi square $\mathrm{p}$ value $=0.0$ ), as seen in Table 4.

The responses to the questions whether it's hard to go to bed, whether they take naps during the day and feel rested after a night's sleep, are significantly different

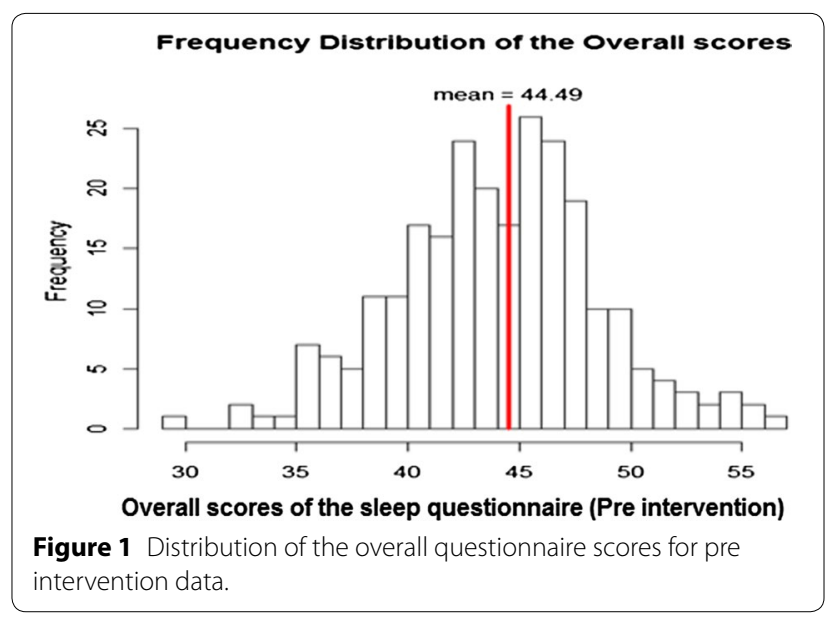

between the 4th and 5th grades using the t-test and the Chi square test. Additionally, t-test showed a significant difference between the grades for the questions of staying up late when parents think they are asleep, whether they sleep too little, if they wake up at night and if they feel sleepy during the day. The summaries of the questions having significant p-values are shown in Table 4.

\section{Post-intervention results}

The Post intervention data is summarized in terms of mean questionnaire scores, comparison between pre and post interventions in terms of proportion of responses to the questionnaire, Chi square and t-tests.

The overall questionnaire scores have a mean of 39 and median of 38, which has decreased compared to the preintervention mean and median score of 45 (Figure 2).

For most of the questions, responses have improved by the post-intervention. Among the different blocks, block 1 (Bedtime resistance) has the biggest change in the percentages of responses. Students who usually slept in the same bed increased from 21 to $76 \%$. Students who were not ready to sleep at the usual bedtime are $26 \%$, which decreased from $52 \%$ previously. Those who stayed up late decreased from 31 to $13 \%$. It increased to $56 \%$ of students whom usually felt rested after a good night's sleep, which was previously $32 \%$. The percentages of responses are detailed in Table 5.

Table 1 Total sample and missing data

\begin{tabular}{|c|c|c|c|c|c|c|}
\hline & \multicolumn{3}{|c|}{ Pre-intervention } & \multicolumn{3}{|c|}{ Post-intervention } \\
\hline & Grade 4 & Grade 5 & Both & Grade 4 & Grade 5 & Both \\
\hline Total number of students & 166 & 98 & 264 & 165 & 98 & 263 \\
\hline Missing data for at least 1 question & 13 & 3 & 10 & 12 & 6 & 18 \\
\hline Response to all questions & 153 & 95 & 254 & 153 & 92 & 245 \\
\hline
\end{tabular}


Table 2 Sleep questionnaire with answers are coded as (1), (2), and (3)

\begin{tabular}{|c|c|c|c|c|}
\hline & Questionnaire & Answers & & \\
\hline 1 & Who in your family sets the rules about when you got to bed? & & & \\
\hline 2 & Do you have trouble sleeping & Yes (2) & No (1) & \\
\hline \multirow[t]{2}{*}{3} & Do you like to sleep & Yes (1) & No (2) & \\
\hline & Block 1-bedtime resistance & & & \\
\hline 4 & Do you go to bed at same time every night on school nights? & Usually (1) & Sometimes (2) & Rarely (3) \\
\hline 5 & Do you fall asleep in the same bed every night? & Usually (1) & Sometimes (2) & Rarely (3) \\
\hline 6 & Do you fall asleep alone? & Usually (1) & Sometimes (2) & Rarely (3) \\
\hline 7 & Do you fall asleep in parents', brother's or sister's bed? & Usually (3) & Sometimes (2) & Rarely (1) \\
\hline 9 & Do you fight with your parents about going to bed? & Usually (3) & Sometimes (2) & Rarely (1) \\
\hline 10 & Is it hard for you to go to bed? & Usually (3) & Sometimes (2) & Rarely (1) \\
\hline 11 & Are you ready for bed at your usual bedtime? & Usually (1) & Sometimes (2) & Rarely (3) \\
\hline \multirow[t]{2}{*}{15} & Do you stay up late when your parents think you are asleep? & Usually (3) & Sometimes (2) & Rarely (1) \\
\hline & Block 2-sleep onset delay & & & \\
\hline \multirow[t]{2}{*}{8} & Do you fall asleep in about 20 minutes? & Usually (1) & Sometimes (2) & Rarely (3) \\
\hline & Block 3-sleep anxiety & & & \\
\hline 12 & Do you have a special thing you bring to bed? & Usually (3) & Sometimes (2) & Rarely (1) \\
\hline 13 & Are you afraid of the dark? & Usually (3) & Sometimes (2) & Rarely (1) \\
\hline \multirow[t]{2}{*}{14} & Are you afraid of sleeping alone? & Usually (3) & Sometimes (2) & Rarely (1) \\
\hline & Block 4-sleep duration & & & \\
\hline 16 & Do you think you sleep too little? & Usually (3) & Sometimes (2) & Rarely (1) \\
\hline \multirow[t]{2}{*}{17} & Do you think you sleep too much? & Usually (3) & Sometimes (2) & Rarely (1) \\
\hline & Block 5-night waking's & & & \\
\hline 18 & Do you wake up at night when parents think you are asleep? & Usually (3) & Sometimes (2) & Rarely (1) \\
\hline 19 & Do you have trouble falling back to sleep if you wake up during the night? & Usually (3) & Sometimes (2) & Rarely (1) \\
\hline 20 & Do you have nightmares? & Usually (3) & Sometimes (2) & Rarely (1) \\
\hline 21 & Does pain wake you up at night? Where is that pain? & Usually (3) & Sometimes (2) & Rarely (1) \\
\hline \multirow[t]{2}{*}{22} & Do you sometimes go to someone else bed during the night? If yes who? & Usually (3) & Sometimes (2) & Rarely (1) \\
\hline & Block 6-daytime sleepiness & & & \\
\hline 23 & Do you have trouble waking up in the morning? & Usually (3) & Sometimes (2) & Rarely (1) \\
\hline 24 & Do you feel sleepy during the day? & Usually (3) & Sometimes (2) & Rarely (1) \\
\hline 25 & Do you take naps during the day? & Usually (3) & Sometimes (2) & Rarely (1) \\
\hline 26 & Do you feel rested after a night's sleep? & Usually (1) & Sometimes (2) & Rarely (3) \\
\hline
\end{tabular}

There is a significant decrease in the percent of students who had trouble sleeping, from 56 to $23 \%$ after intervention (Chi square p value $=0.0$ ) as seen in Table 6. Out of the 25 questions, Chi square tests showed statistically significant difference between the pre and post-intervention data for 15 questions. For most questions in Block 1, Block 3 and Block 5, there is a significant difference between the pre and postintervention as shown by Chi square tests (Table 7). The t-tests showed similar results to the Chi square tests. The overall questionnaires mean scores are statistically significant between the pre and post groups $(\mathrm{p}$ value $=0)$. $\mathrm{T}$ tests showed that mean scores for Block 1: Bedtime Resistance ( $\mathrm{p}$ value $=0$ ), Block 3:
Sleep anxiety ( $\mathrm{p}$ value $=0$ ) and Block 5 : Night awakenings ( $p$ value -0 ), are all statistically significant between pre and post-intervention data. The mean scores in Block 2, Block 4 and Block 6, Daytime Sleepiness and Sleep Duration were not significantly different (Table 7).

\section{Discussion}

Our study aimed at assessing baseline sleep habits and behaviors in elementary school children. Baseline data indicated a significant percentage of students have sleep problems. These findings are consistent with the previous studies done on elementary school children (Owens et al. 2000; Mindell et al. 2009; Blader et al. 1997). 
Table 3 Response percentages to the questionnaire (pre intervention data)

\begin{tabular}{|c|c|c|c|c|}
\hline \multicolumn{5}{|c|}{ Response percentages to the questionnaire (pre intervention data, both grades combined) } \\
\hline \multicolumn{2}{|l|}{ Quest\# } & \multirow{2}{*}{$\begin{array}{l}\text { Yes (\%) } \\
55.56\end{array}$} & \multirow{2}{*}{$\begin{array}{l}\text { No (\%) } \\
44.44\end{array}$} & \\
\hline 2 & Trouble sleeping & & & \\
\hline \multirow[t]{3}{*}{3} & Likes to sleep & 78.79 & 21.21 & \\
\hline & & Rarely (\%) & Sometimes (\%) & Usually (\%) \\
\hline & Bedtime resistance & & & \\
\hline 4 & Goes to bed at same time & 38.64 & 32.20 & 29.17 \\
\hline 5 & Falls asleep in same bed & 50.95 & 28.14 & 20.91 \\
\hline 6 & Sleeps alone & 47.73 & 27.27 & 25.00 \\
\hline 7 & Falls asleep in other's bed & 41.06 & 30.80 & 28.14 \\
\hline 9 & Fights with parents to go to bed & 58.71 & 31.06 & 10.23 \\
\hline 10 & Hard to go to bed & 39.69 & 32.44 & 27.86 \\
\hline 11 & Ready to sleep at usual bedtime & 51.52 & 25.00 & 23.48 \\
\hline \multirow[t]{2}{*}{15} & Stay up late when parents think you are asleep & 41.29 & 28.03 & 30.68 \\
\hline & Sleep duration & & & \\
\hline \multirow[t]{2}{*}{8} & Falls asleep in 20 min & 31.44 & 35.61 & 32.95 \\
\hline & Sleep anxiety & & & \\
\hline 12 & Take a special thing to bed & 44.70 & 33.33 & 21.97 \\
\hline 13 & Afraid of dark & 51.15 & 25.19 & 23.66 \\
\hline \multirow[t]{2}{*}{14} & Afraid of sleeping alone & 46.59 & 35.98 & 17.42 \\
\hline & Sleep duration & & & \\
\hline 16 & Sleeps too little & 49.43 & 31.56 & 19.01 \\
\hline \multirow[t]{2}{*}{17} & Sleeps too much & 53.79 & 30.68 & 15.53 \\
\hline & Night awakening & & & \\
\hline 18 & Wakes up at night when parents think you are asleep & 56.82 & 29.17 & 14.02 \\
\hline 19 & Trouble falling back asleep after waking up & 51.89 & 31.06 & 17.05 \\
\hline 20 & Have nightmares & 48.11 & 33.71 & 18.18 \\
\hline 21 & Wakes up due to pain & 53.08 & 33.08 & 13.85 \\
\hline \multirow[t]{2}{*}{22} & Goes to other's bed during night & 53.23 & 35.74 & 11.03 \\
\hline & Daytime sleepiness & & & \\
\hline 23 & Trouble waking up in morning & 44.70 & 34.85 & 20.45 \\
\hline 24 & Feels sleepy during day & 48.11 & 39.77 & 12.12 \\
\hline 25 & Take naps during day & 55.30 & 29.55 & 15.15 \\
\hline 26 & Feels rested after a night's sleep & 35.74 & 31.94 & 32.32 \\
\hline
\end{tabular}

\section{Baseline prevalence of sleep problems}

In the present study, a high percent of students experienced problems in the areas of bedtime resistance, sleep onset delay, sleep anxiety, night awakenings and daytime sleepiness. Proportions of students affected by certain sleep problems are very similar to previous studies while other sleep problems affect a higher percentage of students.

The highest percentages of challenges were found in the Bedtime Resistance Category. $41 \%$ showed resistance with parents to go to bed at least 2 nights a week, with $10 \%$ showing resistance $5-7$ nights a week. This result is in line with other studies. A single bed time resistance item on the CSHQ, $37.6 \%$ of the sample reported this behavior at least two times a week (Owens et al. 2000). In another study $27 \%$ children showed bedtime resistance (Blader et al. 1997). National Sleep Foundation (NSF) poll reported that $42 \%$ children stall to go to bed (Mindell et al. 2009). 20\% of children in our study had trouble waking up 5-7 days/week. NSF poll reported $29 \%$ had difficulty waking in the morning at least a few days or nights a week (Mindell et al. 2009) and 17\% had morning wake up problems according to (Blader et al. 1997).

Our study showed higher percentages of sleep-onset delays, whereas $31 \%$ rarely slept within $20 \mathrm{~min}$. NSF poll reported $22 \%$ take more than 20 min to fall asleep 
Table 4 Comparing pre-intervention data between Grade 4 and 5

\begin{tabular}{|c|c|c|c|c|c|c|c|c|c|}
\hline \multicolumn{10}{|c|}{ Comparing pre-intervention data between Grade 4 and 5} \\
\hline \multicolumn{2}{|c|}{ Quest \# } & \multicolumn{2}{|l|}{ Grade 4} & \multicolumn{3}{|l|}{ Grade 5} & \multirow{2}{*}{\multicolumn{2}{|c|}{$t$ test }} & \multirow[t]{2}{*}{ chisc } \\
\hline & & Yes (\%) & No (\%) & Yes (\%) & & No (\%) & & & \\
\hline 2 & Trouble sleeping & 63.80 & 36.20 & 42.86 & & 57.14 & - & & $0.00^{*}$ \\
\hline \multirow[t]{2}{*}{3} & Likes to sleep & 79.52 & 20.48 & 77.55 & & 22.45 & - & & 0.82 \\
\hline & & & Rarely (\%) & Usually (\%) & Rarely ( & (\%) & Usually (\%) & $t$ test & chisq \\
\hline 10 & Hard to go to bed & & 45.18 & 22.89 & 30.21 & & 36.46 & $0.01^{*}$ & $0.02^{*}$ \\
\hline 11 & Ready to sleep at usual bedt & & 48.80 & 23.49 & 56.12 & & 23.47 & 0.53 & $0.00^{*}$ \\
\hline 15 & Stay up late when parents th & e asleep & 37.35 & 34.34 & 47.96 & & 24.49 & $0.05^{*}$ & 0.16 \\
\hline 16 & Sleeps too little & & 54.55 & 16.36 & 40.82 & & 23.47 & $0.04^{*}$ & 0.09 \\
\hline 18 & Wakes up at night when pare & you are asleep & 53.61 & 17.47 & 62.24 & & 8.16 & $0.05^{*}$ & 0.1 \\
\hline 24 & Feels sleepy during day & & 52.41 & 9.04 & 40.82 & & 17.35 & $0.03^{*}$ & 0.07 \\
\hline 25 & Takes naps during day & & 59.04 & 9.64 & 48.98 & & 24.49 & $0.01^{*}$ & $0.01^{*}$ \\
\hline 26 & Feels rested after a night's sle & & 30.30 & 39.39 & 44.90 & & 20.41 & $0.00^{*}$ & $0.00^{*}$ \\
\hline
\end{tabular}

* Statistically significant $(p<0.05)$.

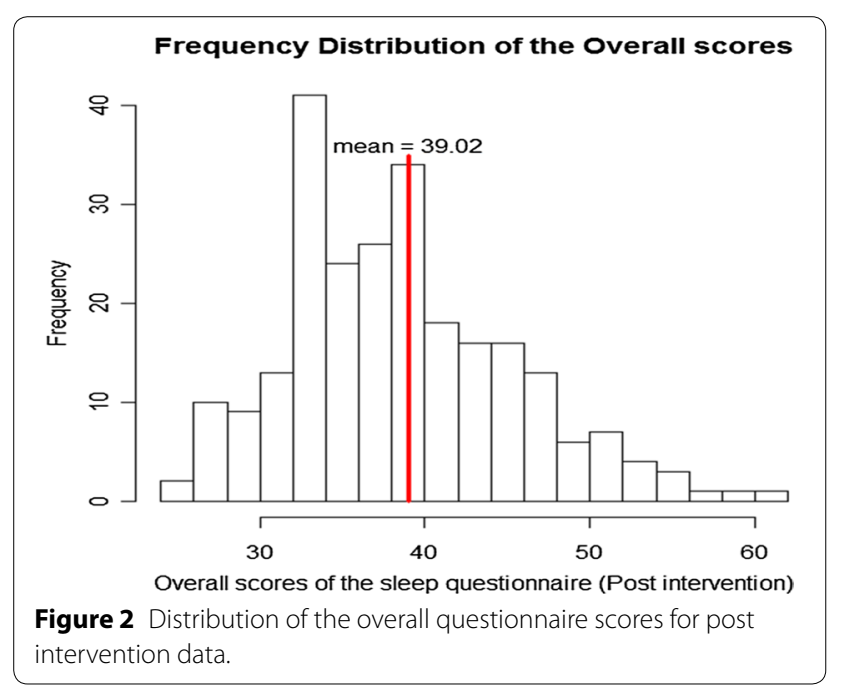

(Mindell et al. 2009) whereas $11.3 \%$ had sleep-onset delays. Similarly we found $43 \%$ reported night wakening at least 2 times a week and 14\% wakening at least 5 times a week, which is higher than $27 \%$ night wakening at least 2 times a week, for the single item question in CSHQ (16) and 14\% children waking at least one time per night (Mindell et al. 2009). We found that 55\% take a nap rarely whereas NSF poll reported $94 \%$ took no nap at all (Mindell et al. 2009).

\section{Effect of intervention on sleep patterns and habits}

The study compared sleep patterns and habits through the pre and post interventions. We noticed an improvement in the sleep behaviors especially in the areas of bedtime resistance, sleep anxiety and night awakening after the KNIGHTS program. There is a significant decrease in the percent of students who had trouble sleeping, from 56 to $23 \%$ after the intervention, suggesting the effectiveness of video base and Q\&A programs.

Studies have reported that sleep education resulted in improved sleep behavior (Rossi et al. 2002) and increased sleep duration (Rossi et al. 2002; Blunden et al. 2012; Vo et al. 2003; Bakotic et al. 2009). Previous studies that measured changes in sleep parameters (e.g., sleep hygiene practices and sleep duration), showed mixed results. Some studies showed improvement with sleep hygiene whereas another study reported earlier bed and wake times on both school and weekend nights for students receiving sleep education (Vo et al. 2003).

School based sleep programs seek to improve sleep knowledge using different education programs assuming that will improve sleep habits. Many studies have showed that sleep knowledge significantly increased with school based sleep education program (Moseley and Gradisar 2009; Blunden et al. 2012; Bakotic et al. 2009; De Sousa IC et al. 2007; Cortesi et al. 2004; Cain et al. 2011; Azevedo et al 2008; Cassoff et al. 2013). However, schoolbased sleep promotion programs usually do not succeed in improving and maintaining sleep behavioral changes (Blunden et al. 2012; Cassoff et al. 2013). Sleep parameters such as sleep patterns, sleep quality and sleep habits did not change significantly after the sleep programs (Moseley and Gradisar 2009; Vo et al. 2003; De Sousa IC et al. 2007; Cain et al. 2011). In addition to sleep education, some programs have used cognitive and behavioral strategies, but they have not been very successful in improving sleep behavior (Moseley and Gradisar 2009).

Studies have reported the benefits of school-based programs to educate and improve behaviors in adolescents 
Table 5 Response Percentages comparing pre-intervention and post intervention data

\begin{tabular}{|c|c|c|c|c|c|}
\hline \multirow[t]{2}{*}{ Quest \# } & \multirow[t]{2}{*}{ Response percentages to the questionnaire } & \multicolumn{2}{|c|}{ Pre intervention } & \multicolumn{2}{|c|}{ Post intervention } \\
\hline & & Rarely (\%) & Usually (\%) & Rarely (\%) & Usually (\%) \\
\hline & Bedtime resistance & & & & \\
\hline 4 & Goes to bed at same time & 38.64 & 29.17 & $20.15^{*}$ & $38.40^{*}$ \\
\hline 5 & Falls asleep in same bed & 50.95 & 20.91 & $5.72^{*}$ & $75.95^{*}$ \\
\hline 6 & Sleeps alone & 47.73 & 25.00 & $14.88^{*}$ & $67.94^{*}$ \\
\hline 7 & Falls asleep in other's bed & 41.06 & 28.14 & $73.18^{*}$ & $13.79^{*}$ \\
\hline 9 & Fights with parents to go to bed & 58.71 & 10.23 & 62.74 & 12.93 \\
\hline 10 & Hard to go to bed & 39.69 & 27.86 & $53.82^{*}$ & $15.23^{*}$ \\
\hline 11 & Ready to sleep at usual bedtime & 51.52 & 23.48 & $25.67^{*}$ & $34.87^{*}$ \\
\hline \multirow[t]{2}{*}{15} & Stay up late when parents think you are asleep & 41.29 & 30.68 & $57.41^{*}$ & $12.55^{*}$ \\
\hline & Sleep onset delay & & & & \\
\hline \multirow[t]{2}{*}{8} & Falls asleep in 20 min & 31.44 & 32.95 & $29.39^{*}$ & 29.01 \\
\hline & Sleep anxiety & & & & \\
\hline 12 & Takes a special thing to bed & 44.70 & 21.97 & 50.38 & 30.92 \\
\hline 13 & Afraid of dark & 51.15 & 23.66 & $70.34^{*}$ & $12.93^{*}$ \\
\hline \multirow[t]{2}{*}{14} & Afraid of sleeping alone & 46.59 & 17.42 & $76.05^{*}$ & $5.70^{*}$ \\
\hline & Sleep Duration & & & & \\
\hline 16 & Sleeps too little & 49.43 & 19.01 & 49.43 & $12.55^{*}$ \\
\hline \multirow[t]{2}{*}{17} & Sleeps too much & 53.79 & 15.53 & $56.65^{*}$ & $9.88^{*}$ \\
\hline & Night awakening & & & & \\
\hline 18 & Wakes up at night when parents think you are asleep & 56.82 & 14.02 & 54.75 & $12.93^{*}$ \\
\hline 19 & Trouble falling back asleep after waking up & 51.89 & 17.05 & 43.89 & 19.47 \\
\hline 20 & Have nightmares & 48.11 & 18.18 & 64.89 & $8.40^{*}$ \\
\hline 21 & Wakes up due to pain & 53.08 & 13.85 & 68.46 & $7.69^{*}$ \\
\hline \multirow[t]{2}{*}{22} & Goes to other's bed during night & 53.23 & 11.03 & 71.37 & $6.49^{*}$ \\
\hline & Daytime sleepiness & & & & \\
\hline 23 & Trouble waking up in morning & 44.70 & 20.45 & 35.50 & 24.05 \\
\hline 24 & Feels sleepy during day & 48.11 & 12.12 & 38.55 & 14.89 \\
\hline 25 & Takes naps during day & 55.30 & $15.15 \%$ & 61.83 & $12.21^{*}$ \\
\hline 26 & Feels rested after a night's sleep & 35.74 & 32.32 & $16.41^{*}$ & 55.73 \\
\hline
\end{tabular}

* Denotes an increase in the percentage of students who have responded positively post intervention.

Table 6 Comparing pre-intervention and post intervention data (questions 2 and 3)

\begin{tabular}{|c|c|c|c|c|c|c|}
\hline \multirow[t]{2}{*}{ Quest \# } & & \multicolumn{2}{|c|}{ Pre intervention } & \multicolumn{2}{|c|}{ Post intervention } & \multirow[t]{2}{*}{ Chisq ( $p$ value) } \\
\hline & & Yes (\%) & No (\%) & Yes (\%) & No (\%) & \\
\hline 2 & Trouble sleeping & 56 & 44 & 23 & 77 & $0.00^{*}$ \\
\hline 3 & Likes to sleep & 79 & 21 & 77 & 23 & 0.82 \\
\hline
\end{tabular}

* Denotes significant $p$ values at 0.05 significance level

for many health related issues such as diet, physical activity, eating disorders, drug abuse and depression (Wade et al. 2003; Orlando et al. 2005; Possel et al. 2005; Kitzman-Ulrich et al. 2010; Harris et al. 2009; Hatzis and Kafatos 2010).

Interactive programs with student participation are more effective than brief lecture-style programs in changing behavior (Clarke et al. 1993; Stice and Shaw 2004). No standardized assessment measures exist for testing sleep knowledge in children. Hence studies construct and develop their own questionnaires. Blunden et al. therefore highlight the need of use for a standard sleep knowledge measure (Blunden et al. 2012). 
Table 7 Comparing pre-intervention and post intervention data (Grades 4 and 5 combined)

\begin{tabular}{|c|c|c|c|}
\hline \multicolumn{4}{|c|}{ Comparing pre-intervention and post intervention data } \\
\hline & & t test & chisq \\
\hline & Questions 2 to 26 (overall score) & $0.00^{*}$ & $N A^{* *}$ \\
\hline & Block 1—Bedtime Resistance & $0.00^{*}$ & NA \\
\hline 4 & Do you go to bed at same time every night on school nights? & $0.00^{*}$ & $0.00^{*}$ \\
\hline 5 & Do you fall asleep in same bed every night? & $0.00^{*}$ & $0.00^{*}$ \\
\hline 6 & Do you fall asleep alone? & $0.00^{*}$ & $0.00^{*}$ \\
\hline 7 & Do you falls asleep in parents', brother's or sister's bed? & $0.00^{*}$ & $0.00^{*}$ \\
\hline 9 & Do you fight with your parents about going to bed? & 0.81 & 0.19 \\
\hline 10 & Is it hard for you to go to bed? & $0.00^{*}$ & $0.00^{*}$ \\
\hline 11 & Are you ready for bed at your usual bedtime? & $0.00^{*}$ & $0.00^{*}$ \\
\hline \multirow[t]{2}{*}{15} & Do you stay up late when parents think you are asleep? & $0.00^{*}$ & $0.00^{*}$ \\
\hline & Block 2-sleep onset delay & & \\
\hline \multirow[t]{2}{*}{8} & Do you fall asleep in about $20 \mathrm{~min} ?$ & 0.72 & 0.36 \\
\hline & Block 3-sleep anxiety & $0.00^{*}$ & NA \\
\hline 12 & Do you have a special thing you bring to bed? & 0.68 & $0.00^{*}$ \\
\hline 13 & Are you afraid of the dark? & $0.00^{*}$ & $0.00^{*}$ \\
\hline \multirow[t]{2}{*}{14} & Are you afraid of sleeping alone? & $0.00^{*}$ & $0.00^{*}$ \\
\hline & Block 4-sleep duration & 0.10 & NA \\
\hline 16 & Do you think you sleep too little? & 0.28 & 0.08 \\
\hline \multirow[t]{2}{*}{17} & Do you think you sleep too much? & 0.20 & 0.15 \\
\hline & Block 5-night awakening & $0.00^{*}$ & NA \\
\hline 18 & Do you wake up at night when parents think you are asleep? & 0.86 & 0.73 \\
\hline 19 & Do you have trouble falling back to sleep if you wake up during the night? & 0.12 & 0.18 \\
\hline 20 & Do you have nightmares? & $0.00^{*}$ & $0.00^{*}$ \\
\hline 21 & Does pain wake you up at night? Where is that pain? & $0.00^{*}$ & $0.00^{*}$ \\
\hline \multirow[t]{2}{*}{22} & Do you sometimes go to someone's bed during the night? If yes who? & $0.00^{*}$ & $0.00^{*}$ \\
\hline & Block 6—daytime sleepiness & 0.07 & NA \\
\hline 23 & Do you have trouble waking up in the morning? & 0.07 & 0.10 \\
\hline 24 & Do you feel sleepy during the day? & 0.06 & 0.09 \\
\hline 25 & Do you take naps during the day? & 0.13 & 0.30 \\
\hline 26 & Do you feel rested after a night's sleep? & $0.00^{*}$ & $0.00^{*}$ \\
\hline
\end{tabular}

* Denotes significant $\mathrm{p}$-values at 0.05 significance level.

**NA not applicable.

\section{Limitations and future directions}

Our study has several limitations. The study sample had a Hispanic ethnicity predominance of $52 \%$ children being of Hispanic ethnicity. However no data was collected on the race/ethnicity of individual students. We also did not collect any information regarding the gender of the students. Hence the responses were not classified according to ethnicity and gender.

Ethnicity and gender have significant effects on sleep behaviors. Non-Caucasian children reported later bedtimes and had shorter sleep duration than Caucasian children (Biggs et al. 2013; Gulliford et al. 1990; Liu et al. 2005; Spilsbury et al. 2004). Previous studies have reported that boys had shorter sleep duration than girls on non-school nights (Biggs et al. 2013; Gulliford et al. 1990; Liu et al. 2005; Ng et al. 2005). Moore et al. (2011) found that gender and minority ethnicity was significantly associated with sleep duration, with girls and non-minority adolescents obtaining more sleep. Another sleep study conducted on minority children found that gender had significant effect on sleep duration, where girls aged $11-12$ year slept $0.3 \mathrm{~h}$ /days less than boys (Wong et al. 2013). Presence of TVs in the child's bedroom contributes to sleep problems (Owens et al. 1999) and a higher percent of Hispanic (74\%) children compared with white children (22\%) have TVs in their bedroom (Taveras et al. 2009). Sleep education with educational leaflets was more effective in female adolescents compared to male adolescents (Bakotic and Koscec 2009). Identifying the gender and racial makeup of the sample will give more insight into the sleep problems and effectiveness of treatments. 
In previous studies using CSHQ, the questionnaire was answered by students, teachers and/or parents (Iwadare et al. 2013; Owens et al. 2000). Their responses were correlated to get a better picture of the sleep behaviors. It has also been shown that parents can influence children's sleep habits (Brand et al. 2009). Our study has only the student's answer the questionnaire. In future studies, we will include parents and teachers to take the questionnaire as well, which will help us to objectively evaluate sleep habits and behavior.

Students were retested with the questionnaire 4 months after the intervention and the results showed significant results. This is evidence that our KNIGHTS program is successful. However, all the students who answered the pre-intervention questionnaire underwent the intervention and there was no control class or students unlike some previous studies, which have used controls (Brown et al. 2006) and randomized controlled design (Moseley and Gradisar 2009; Rossi et al 2002; Vo et al. 2003; Bakotic et al. 2009; Cortesi et al. 2004). Therefore we cannot completely exclude other factors influencing this improved sleep behavior. Future studies are suggested to look into these issues.

\section{Conclusion}

There are significant sleep issues among elementary school children. The KNIGHTS sleep education program has been beneficial. The study demonstrated an increase in positive sleep behaviors and decrease in sleep problems. Our study is not without limitations. Future studies can include gender and racial make-up of the sample, involving parents and teachers in the program, using controls and the study, a randomized controlled study. Beneficial effect of the video based learning provides another venue for the educator to look into, to improve the sleep habits and behavior.

\begin{abstract}
Authors' contributions
SRS was involved in study design, implementation, writing and editing of manuscript. SSS, SSS and ZS conducted the program and data collection. AK was involved in writing of manuscript. SS was involved in statistical analysis and review of manuscript. All authors read and approved the final manuscript.

\section{Author details}

${ }^{1}$ Texas A\&M University, 1177 West Wheeler Ave, Suite 1, Aransas Pass, TX 78336, USA. ${ }^{2}$ Pulmonary Associates, Corpus Christi, TX, USA. ${ }^{3}$ University of California, Berkeley, CA, USA. ${ }^{4}$ Harvard University, Cambridge, MA, USA.
\end{abstract}

\section{Acknowledgement \\ Authors thank all the school teachers and counselors for their support.}

\section{Compliance with ethical guidelines}

\section{Competing interest}

None of the authors have any conflict of interest to disclose. The Movie was provided by the It's Your Life Foundation, and the educational program was done by the investigator and volunteers from Pulmonary Associates. Neither pulmonary Associates nor any investigators received any monetary or in-kind reimbursement from the It's your Life Foundation.

\section{Ethical approval}

Permission was obtained from the CCISD (Corpus Christi Independent school District) as a part of broader sleep education program.

Received: 28 March 2015 Accepted: 1 July 2015

Published online: 14 July 2015

\section{References}

Anderson B, Storfer-Isser A, Taylor HG, Rosen CL, Redline S (2009) Associations of executive function with sleepiness and sleep duration in adolescents. Pediatrics 123(4):e701-e707. doi:10.1542/peds.2008-1182

Azevedo CV, Sousa I, Paul K, MacLeish MY, Mondejar MT, Sarabia JA et al (2008) Teaching chronobiology and sleep habits in school and university. Mind Brain Educ 2(1):34-46

Bakotic MR-VB, Koscec A (2009) Educating adolescents about healthy sleep: experimental study of effectiveness of educational leaflet. Public Health 50:174-181. doi:10.3325/cmj.2009.50.174

Bakotic M, Radosevic-Vidacek B, Koscec A (2009) Educating adolescents about healthy sleep: experimental study of effectiveness of educational leaflet. Croat Med J 50(2):174-181

Biggs SN, Lushington K, James Martin A, van den Heuvel C, Declan Kennedy J (2013) Gender, socioeconomic, and ethnic differences in sleep patterns in school-aged children. Sleep Med 14(12):1304-1309. doi:10.1016/j. sleep.2013.06.014

Blader JC, Koplewicz HS, Abikoff H, Foley C (1997) Sleep problems of elementary school children. A community survey. Arch Pediatr Adolesc Med 151(5):473-480

Blunden SL, Chapman J, Rigney GA (2012) Are sleep education programs successful? The case for improved and consistent research efforts. Sleep Med Rev 16(4):355-370. doi:10.1016/j.smrv.2011.08.002

Brand S, Gerber M, Hatzinger M, Beck J, Holsboer-Trachsler E (2009) Evidence for similarities between adolescents and parents in sleep patterns. Sleep Med 10(10):1124-1131. doi:10.1016/j.sleep.2008.12.013

Brown FC, Buboltz WC Jr, Soper B (2006) Development and evaluation of the Sleep Treatment and Education Program for Students (STEPS). J Am Coll Health J ACH 54(4):231-237. doi:10.3200/JACH.54.4.231-237

Cain N, Gradisar M, Moseley L (2011) A motivational school-based intervention for adolescent sleep problems. Sleep Med 12(3):246-251. doi:10.1016/j. sleep.2010.06.008

Carksadon MA, Mindell J, Drake C (2006) Contemporary Sleep Patterns of Adolescents in the USA: Results of the 2006 National Sleep Foundation Sleep in America Poll. J Sleep Research 15 (42)

Carskadon MA, Wolfson AR, Acebo C, Tzischinsky O, Seifer R (1998) Adolescent sleep patterns, circadian timing, and sleepiness at a transition to early school days. Sleep 21(8):871-881

Cassoff J, Knauper B, Michaelsen S, Gruber R (2013) School-based sleep promotion programs: effectiveness, feasibility and insights for future research. Sleep Med Rev 17(3):207-214. doi:10.1016/j.smrv.2012.07.001

Clarke GNHW, Murphy W, Sheeber L (1993) School-based primary prevention of depressive symptomatology in adolescents. Findings from two studies. J Adolesc Res 8(2):183-204. doi:10.1177/074355489382004

Cortesi F, Giannotti F, Sebastiani T, Bruni O, Ottaviano S (2004) Knowledge of sleep in Italian high school students: pilot-test of a school-based sleep educational program. J Adolesc Health 34(4):344-351. doi:10.1016/j. jadohealth.2003.07.003

Crowley SJ, Acebo C, Fallone G, Carskadon MA (2006) Estimating dim light melatonin onset (DLMO) phase in adolescents using summer or schoolyear sleep/wake schedules. Sleep 29(12):1632-1641

De Sousa IC, Araújo JF, De Azevedo CVM (2007) The effect of a sleep hygiene education program on the sleep-wake cycle of Brazilian adolescent students. Sleep Biol Rhythm 5(4):251-258. doi:10.1111/ j.1479-8425.2007.00318.x

Gulliford MC, Price CE, Rona RJ, Chinn S (1990) Sleep habits and height at ages 5 to 11. Arch Dis Child 65(1):119-122

Harris KC, Kuramoto LK, Schulzer M, Retallack JE (2009) Effect of schoolbased physical activity interventions on body mass index in children: a meta-analysis. CMAJ Can Med Assoc J J Assoc Med Can 180(7):719-726. doi:10.1503/cmaj.080966 
Hatzis CMPC, Kafatos AG (2010) School health education programs in Crete: evaluation of behavioural and health indices a decade after initiation. Prev Med 51(3-4):262-267. doi:10.1016/j.ypmed.2010.05.015

Iwadare YKY, Oiji A, Adoi Y, Usami M, Kodaira M, Watanabe K, Saito K (2013) Study of the sleep patterns, sleep habits and sleep problems in Japanese elementary school children using the CHSQ-J. Kitasata Med J 43:31-37

Kitzman-Ulrich H, Wilson DK, St George SM, Lawman H, Segal M, Fairchild A (2010) The integration of a family systems approach for understanding youth obesity, physical activity, and dietary programs. Clin Child Fam Psychol Rev 13(3):231-253. doi:10.1007/s10567-010-0073-0

Liu X, Liu L, Owens JA, Kaplan DL (2005) Sleep patterns and sleep problems among schoolchildren in the United States and China. Pediatrics 115(1 Suppl):241-249. doi:10.1542/peds.2004-0815F

Mercer PW, Merritt SL, Cowell JM (1998) Differences in reported sleep need among adolescents. J Adolesc Health 23(5):259-263

Mindell JA, Meltzer LJ, Carskadon MA, Chervin RD (2009) Developmental aspects of sleep hygiene: findings from the 2004 National Sleep Foundation Sleep in America Poll. Sleep Med 10(7):771-779. doi:10.1016/j. sleep.2008.07.016

Moore M, Kirchner HL, Drotar D, Johnson N, Rosen C, Redline S (2011) Correlates of adolescent sleep time and variability in sleep time: the role of individual and health related characteristics. Sleep Med 12(3):239-245. doi:10.1016/j.sleep.2010.07.020

Moseley L, Gradisar M (2009) Evaluation of a school-based intervention for adolescent sleep problems. Sleep 32(3):334-341

Ng DK, Kwok KL, Cheung JM, Leung SY, Chow PY, Wong WH et al (2005) Prevalence of sleep problems in Hong Kong primary school children: a community-based telephone survey. Chest 128(3):1315-1323. doi:10.1378/chest.128.3.1315

$\mathrm{Ng}$ EP, Ng DK, Chan CH (2009) Sleep duration, wake/sleep symptoms, and academic performance in Hong Kong secondary school children. Sleep Breath 13(4):357-367. doi:10.1007/s11325-009-0255-5

Nixon GM, Thompson JM, Han DY, Becroft DM, Clark PM, Robinson E et al (2008) Short sleep duration in middle childhood: risk factors and consequences. Sleep 31(1):71-78

Noland H, Price JH, Dake J, Telljohann SK (2009) Adolescents'sleep behaviors and perceptions of sleep. J Sch Health 79(5):224-230. doi:10.1111/j.1746-1561.2009.00402.x

Orlando M, Ellickson PL, McCaffrey DF, Longshore DL (2005) Mediation analysis of a school-based drug prevention program: effects of Project ALERT. Prev Sci 6(1):35-46

Owens J, Maxim R, McGuinn M, Nobile C, Msall M, Alario A (1999) Televisionviewing habits and sleep disturbance in school children. Pediatrics 104(3):e27
Owens JA, Spirito A, McGuinn M (2000a) The Children's Sleep Habits Questionnaire (CSHQ): psychometric properties of a survey instrument for schoolaged children. Sleep 23(8):1043-1051

Owens JA, Spirito A, McGuinn M, Nobile C (2000b) Sleep habits and sleep disturbance in elementary school-aged children. J Develop Behav Pediatr JDBP 21(1):27-36

Possel P, Baldus C, Horn AB, Groen G, Hautzinger M (2005) Influence of general self-efficacy on the effects of a school-based universal primary prevention program of depressive symptoms in adolescents: a randomized and controlled follow-up study. J Child Psychol Psychiatry 46(9):982-994. doi:10.1111/j.1469-7610.2004.00395.x

Rossi CM, Campbell AL, Vo OT, Charron T, Marco CA, Wolfson AR (2002) Middle school sleep-smart program: a pilot evaluation. Sleep 25:A279

Smaldone A, Honig JC, Byrne MW (2007) Sleepless in America: inadequate sleep and relationships to health and well-being of our nation's children. Pediatrics 119(Suppl 1):S29-S37. doi:10.1542/peds.2006-2089F

Spilsbury JC, Storfer-Isser A, Drotar D, Rosen CL, Kirchner LH, Benham H et al (2004) Sleep behavior in an urban US sample of school-aged children. Arch Pediatr Adolesc Med 158(10):988-994. doi:10.1001/ archpedi.158.10.988

Stice E, Shaw H (2004) Eating disorder prevention programs: a meta-analytic review. Psychol Bull 130(2):206-227. doi:10.1037/0033-2909.130.2.206

Taveras EM, Hohman KH, Price S, Gortmaker SL, Sonneville K (2009) Televisions in the bedrooms of racial/ethnic minority children: how did they get there and how do we get them out? Clin Pediatr 48(7):715-719. doi:10.1177/0009922809335667

Vo OKL, Wolfson A, Marco C (2003) Sleepy pre-teens: second pilot of sleepsmart program in 7th grader. Sleep 25:A411

Wade TD, Davidson S, O'Dea JA (2003) A preliminary controlled evaluation of a school-based media literacy program and self-esteem program for reducing eating disorder risk factors. Int J Eat Disord 33(4):371-383. doi:10.1002/eat.10136

Wolfson AR, Carskadon MA (1998) Sleep schedules and daytime functioning in adolescents. Child Dev 69(4):875-887

Wolfson AR, Carskadon MA, Acebo C, Seifer R, Fallone G, Labyak SE et al (2003) Evidence for the validity of a sleep habits survey for adolescents. Sleep 26(2):213-216

Wong WW, Ortiz CL, Lathan D, Moore LA, Konzelmann KL, Adolph AL et al (2013) Sleep duration of underserved minority children in a cross-sectional study. BMC public health 13(1):648. doi:10.1186/1471-2458-13-648

\section{Submit your manuscript to a SpringerOpen ${ }^{\odot}$ journal and benefit from:}

- Convenient online submission

- Rigorous peer review

- Immediate publication on acceptance

- Open access: articles freely available online

- High visibility within the field

- Retaining the copyright to your article

Submit your next manuscript at $>$ springeropen.com 